Cahiers $d u$ MONDE RUSSE

\section{Cahiers du monde russe}

Russie - Empire russe - Union soviétique et États indépendants

$44 / 4 \mid 2003$

Varia

\title{
Contrôle des finances, administration et genèse de l'État dans la Russie de Pierre le Grand
}

\section{Natalia PLATONOVA}

\section{OpenEdition}

\section{Journals}

Édition électronique

URL : https://journals.openedition.org/monderusse/8625

DOI : 10.4000/monderusse.8625

ISSN : $1777-5388$

Éditeur

Éditions de l'EHESS

Édition imprimée

Date de publication : 1 octobre 2003

Pagination : 605-628

ISBN : 2-7132-1833-0

ISSN : $1252-6576$

Référence électronique

Natalia PLATONOVA, « Contrôle des finances, administration et genèse de l'État dans la Russie de Pierre le Grand », Cahiers du monde russe [En ligne], 44/4 | 2003, mis en ligne le 01 janvier 2007, consulté le 03 septembre 2022. URL : http://journals.openedition.org/monderusse/8625; DOI : https://doi.org/10.4000/monderusse.8625 
chercher : repérer : avancer

Cet article est disponible en ligne à l'adresse :

http://www.cairn.info/article.php?ID REVUE=CMR\&ID NUMPUBLIE=CMR 444\&ID ARTICLE=CMR 4440605

\title{
Contrôle des finances, administration et genèse de l'Ét at dans la Russie de Pierre le Grand
}

par Natalia PLATONOVA

\section{Editions de I'EHESS | Cahiers du monde russe}

\author{
2003/4 - Vol 44 \\ ISSN 1252-6576 | ISBN 2713218330 | pages 605 à 628
}

Pour citer cet article :

- PLATONOVA N., Contrôle des finances, administration et genèse de l'Ét at dans la Russie de Pierre le Grand, Cahiers du monde russe 2003/4, Vol 44, p. 605-628.

Distribution électronique Cairn pour les Editions de l'EHESS.

(C) Editions de l'EHESS. Tous droits réservés pour tous pays.

La reproduction ou représentation de cet article, notamment par photocopie, n'est autorisée que dans les limites des conditions générales d'utilisation du site ou, le cas échéant, des conditions générales de la licence souscrite par votre établissement. Toute autre reproduction ou représentation, en tout ou partie, sous quelque forme et de quelque manière que ce soit, est interdite sauf accord préalable et écrit de l'éditeur, en dehors des cas prévus par la législation en vigueur en France. Il est précisé que son stockage dans une base de données est également interdit. 


\section{CONTRÔLE DES FINANCES, ADMINISTRATION ET GENÈSE DE L'ÉTAT DANS LA RUSSIE DE PIERRE LE GRAND}

L'histoire financière de la Russie pétrovienne est connue aujourd'hui dans ses grandes lignes. Il n'est plus possible dans ce domaine de se passer des travaux fondamentaux de Mihail M. Bogoslovskij et Pavel N. Miljukov qui abordèrent le fonctionnement du système politique et économique russe dans son ensemble ${ }^{1}$. L'administration des finances a donné lieu à toute une série d'études dont celle de Dmitrij Tolstoj fut la pionnière ${ }^{2}$. L'historiographie soviétique fut marquée par l'ouvrage de Sergej $\mathrm{M}$. Troickij qui constitue une synthèse générale sur l'évolution des finances monarchiques du XVIII ${ }^{\mathrm{e}}$ siècle, analysant précisément divers aspects des politiques financières et le problème du «budget de l'État $»^{3}$. D'autre part, on connaît mieux l'histoire des impôts directs sous Pierre Ier depuis les travaux de Evgenij V.Anisimov ${ }^{4}$. En revanche, la littérature historique n'a toujours pas traité la question du contrôle qu'exerçait la monarchie russe dans le domaine financier avec le même intérêt et le même soin. Les informations fragmentaires et lacunaires disponibles permettent d'éclairer certains aspects

1. M. M. Bogoslovskij., Oblastnaja reforma Petra Velikogo (La réforme de l'administration locale sous Pierre le Grand), Moscou, Imperatorskoe obščestvo istorii i drevnostej rossijskih pri Moskovskom universitete, 1902 ; P. Miljukov, Gosudarstvennoe hozjajstvo Rossii v pervoj četverti XVIII veka i reformy Petra Velikogo (L'économie nationale dans la Russie du premier quart du XVIII ${ }^{e}$ siècle et les réformes de Pierre le Grand), Saint-Pétersbourg, Tipografija Stasjuleviča, 1905.

2. D. Tolstoj, Istorija finansovyh učreždenij Rossii do konca carstvovanija Ekateriny II (Histoire des institutions financières de la Russie jusqu'à la fin du règne de Catherine II), SaintPétersbourg, Tipografija Ernakova, 1848.

3. S. M. Troickij, Finansovaja politika russkogo absoljutizma v XVIII veke (La politique financière de l'absolutisme russe au XVIII siècle), Moscou, Nauka, 1966.

4. E. V. Anisimov, Podatnaja reforma Petra I : Vvedenie podučnoj podati v Rossii 1719-1728 gg. (La réforme fiscale de Pierre Ir: la création de la capitation en Russie dans les années 17191728), Leningrad, 1982. 
seulement du sujet ${ }^{5}$. Étudier plus systématiquement le contrôle qu'exerçait le pouvoir impérial sur l'ensemble de ses finances, la manière dont il l'a organisé, ouvre pour autant sur des questions essentielles pour la compréhension de l'histoire russe. À commencer par celle de la mise en place, ou non, à l'occasion des réformes pétroviennes - le contrôle des finances en fait partie - d'un État, ou d'une forme nouvelle de l'État qui lui préexistait. Affronter la situation critique dans laquelle l'économie et les finances se retrouvèrent durant la longue guerre du Nord était l'un des soucis majeurs de ces réformes. Mais pour faire face aux problèmes financiers, le pouvoir dut recourir à une série d'expédients qui en atténuèrent la gravité et en retardèrent toutefois la portée et les effets, tels que les manipulations monétaires, la sauvegarde de la monnaie métallique dans le pays, les économies et la réduction des dépenses de la cour. La réforme fiscale adapta au mieux la fiscalité aux besoins du Trésor en augmentant en partie les revenus. On créa non seulement de nouveaux impôts, qui ne tardèrent pas à peser bientôt lourdement sur les contribuables, mais encore on ne négligea pas de réviser les articles des anciennes recettes. Ces mesures eurent une importance indéniable, mais elles laissèrent néanmoins toute leur place à la réorganisation de l'administration fiscale et au contrôle des opérations comptables dont le rôle fut essentiel dans l'ensemble des dispositifs établis. Tout cela conduit à concevoir le contrôle comme une composante indispensable de la politique complexe d'assainissement des finances et de relance économique à laquelle le gouvernement de Pierre Ir eut recours. Un examen approfondi des formes et des procédures du contrôle, à partir d'un corpus de sources les plus diverses, nous permettra d'en reconstituer le mécanisme, mais également de définir la nature et le modèle de contrôle financier développé en Russie, et de préciser son mode de fonctionnement en comparaison des systèmes de contrôle existant ailleurs, en Europe, au même moment.

La fonction de contrôle s'inscrit dans une longue histoire. Elle apparut dès la naissance du pouvoir princier en Russie et accompagna le processus de son unification et de sa centralisation. Au fur et à mesure que la monarchie moscovite se renforçait et que le système financier se compliquait, le contrôle des finances s'organisait progressivement jusqu'à devenir permanent. Au début du XVIII' siècle, il ne se limitait plus au seul domaine du tsar, mais constituait une véritable fonction organisée selon des hiérarchies et des procédures, permettant une investigation des revenus et des richesses de la population dans son ensemble. Les services administratifs et fiscaux, indispensables aux activités réformatrices du tsar en tendant à renforcer son autorité grâce à une meilleure maîtrise de ses finances, purent ainsi être perfectionnés.

Ce processus s'est traduit par le développement extraordinaire des structures de contrôle déjà mises en place et par la recherche constante de nouvelles formes et de nouveaux domaines d'investigation. Le renforcement du contrôle se traduisit en

5. Voir A. I. Konjaev, Finansovyj kontrol' v dorevolucionnoj Rossii (Le contrôle des finances en Russie pré-révolutionnaire), Moscou, Gosfinizdat, 1957 et V. Sakovič, Gosudarstvennyj kontrol' v Rossii, ego istorija i sovremennoe ustrojstvo (Le contrôle d'État en Russie : son histoire et son organisation actuelle), Saint-Pétersbourg, 1896, t. 1. 
effet par son institutionnalisation, sa systématisation et par son extrême spécialisation. Il finit par se transformer en système : c'est d'abord un ensemble d'institutions chargées de contrôler a priori et a posteriori ${ }^{6}$ l'administration financière et c'est ensuite un arsenal de moyens et de procédures en interaction permettant le fonctionnement même de ces instances. Les contrôles - préventif et postérieur - , auxquels s'ajoute le contrôle exceptionnel ${ }^{7}$, formèrent à cette époque une unité administrative dont les principes et les champs d'activité furent définis par un nombre important d'actes législatifs.

En Russie moderne, le tsar incarnait le pouvoir autocratique, détenant le pouvoir de contrôle suprême et des possibilités d'action non limitées. Il se réservait donc le pouvoir de connaître en permanence l'état de ses finances et d'apprécier la sincérité de ses commis. Seul le souverain ne rendait compte à personne de ses actions. Son pouvoir était absolu du fait qu'il agissait sans aucun contrôle de la part de ses sujets. Dans les finances, en tant que seul ordonnateur des dépenses, il bénéficiait d'une irresponsabilité financière totale. Si le tsar était intéressé et le jugeait bon, il pouvait accorder sa grâce aux comptables et les affranchir de toute poursuite de la part des instances de contrôle. Les interventions du monarque réduisaient la portée et l'universalité du contrôle exercé sur ses comptables, ce qui distinguait la fonction de contrôle telle qu'elle était conçue dans la monarchie absolue, aussi bien de celle qui existait auparavant que de celle que nous connaissons encore actuellement.

L'action de contrôle opère d'abord dans le domaine de l'organisation des relations de travail et de subordination. La priorité du service du tsar s'impose par des textes législatifs. Le devoir des commis est d'exercer leurs charges avec diligence et zèle, en connaissant bien la législation, son ignorance entraînant des châtiments :

Il est nécessaire à tous les employés, tant du Sénat, du collège des Affaires ecclésiastiques et autres collèges que des chancelleries et des cours de justice provinciales, de connaître les règlements qui sont d'une grande importance et la première matière dont dépend la bonne et la plus juste gestion de tous les domaines, pour qu'ils servent à chacun pour la fermeté de son honneur, pour éviter de tomber, par ignorance, dans l'erreur et en être châtié. Celui qui ne prendra pas en temps voulu connaissance d'un oukase et ignorera son exécution en se récusant plus tard sous prétexte de ne pas l'avoir vu sera puni : la première fois, par la radiation du rang (čin), la privation du traitement annuel et par l'amende, la deuxième fois, par la privation d'un tiers des biens et, la troisième fois, par la disgrâce totale et par la saisie de tous les biens meubles et immeubles ${ }^{8}$.

6. Le critère de distinction entre ces deux principales formes de contrôle est fondé sur le moment où le contrôle s'exerce. Le contrôle a priori est préalable et préventif. Il s'effectue au cours d'une activité administrative ou financière. Le contrôle a posteriori est postérieur et porte sur la documentation établie au cours de cette action. Il suppose les opérations terminées et imputables aux différents administrateurs ou comptables impliqués.

7. Il constitue un ensemble d'opérations extraordinaires de contrôle destinées à vérifier en peu de temps les activités administratives et financières. C'est un type de contrôle externe exercé par les inspections des finances (revizionnye komissii) et par les juridictions d'exception (rozysknye kanceljarii general-majorov).

8. Polnoe sobranie zakonov Rossijskoj imperii (Recueil complet des lois de l'Empire russe, cité infra PSZ), Saint-Pétersbourg, 1830, t. 7, n 4436. Oukase du 22 janvier 1724 ( $O$ važnosti gosudarstvennyh ustavov »(De l'importance des règlements gouvernementaux)). 
Le Règlement général du 28 février 1720 montre comment la rapidité et l'efficacité de l'action administrative devaient se construire à l'intérieur des nouvelles institutions. Ses nombreux chapitres visaient précisément leur mode de fonctionnement. De haut en bas de l'échelle, les attributions de chaque commis étaient bien déterminées. Tous les employés étaient soumis à un règlement interne strict et à une discipline assez sévère ${ }^{9}$. Il était prévu que les présidents et les vice-présidents des collèges contrôleraient la conduite des employés «incitant chacun d'entre eux à l'honnêteté, à la dignité et au mérite ». De leur côté, si les commis croyaient que leurs supérieurs agissaient à l'encontre des oukases, ils étaient invités à les leur rappeler, à les leur expliquer avec le respect nécessaire ou encore à ne jamais exécuter leurs ordres ${ }^{10}$. Aux yeux de Pierre Ire , le système collégial était un moyen de contrôler le chef d'une institution; il visait à poser des limites à son autorité personnelle dans la gestion : «Les présidents n'ont pas de pouvoirs tels que les juges (sud'i) qui entreprenaient ce qu'ils voulaient. Dans les collèges, le président ne pouvait rien commettre sans l'accord des autres membres. ${ }^{11}$ La collégialité qui servait d'appui au contrôle administratif eut toutefois beaucoup de mal à s'installer. En réalité, les vieilles pratiques administratives cédaient difficilement le pas ${ }^{12}$.

Une autre possibilité de contrôle interne, plus efficace mais peu régulier, se présenta à l'occasion des revues des effectifs. Le pouvoir les organisait pour examiner leur nombre et leurs qualités professionnelles. Le choix d'un personnel compétent et expérimenté était aussi le moyen de se prémunir des abus dans la gestion. La plus importante de ces revues eut lieu à Saint-Pétersbourg en 1722 et impressionna vivement les étrangers. L'un d'eux, le comte Henningue Frédéric de Bassewitz écrivit «qu'énormément d'abus avaient été constatés lors des procèsverbaux » de cette commission ${ }^{13}$. Les commis participant à la revue eurent à répondre à des questionnaires denses qui, selon le kammer-junker Frédéric von

9. N. A. Voskresenskij, Zakonodatel'nye akty Petra I (Les actes législatifs de Pierre Irer), sous la direction et avec une préface de B. I. Syromjatnikov, Moscou, Izdatel'stvo Akademii nauk, 1945, t. 1, p. 482-512. Règlement général de 1720, art. 7 («Ob otsutstvii členov» (Sur le déroulement des affaires en l'absence des membres du collège)), art. 8 ( $O$ razdelenii trudov » (Sur la distribution des tâches parmi les membres du collège)), art. 18 ( $O$ nehoždenii ni za kem v domy » (Sur l'interdiction d'envoyer chercher les membres absents chez eux)), art. 21 ( $O$ vhoždenii i razgovorah v kollegii » (Sur l'autorisation d'entrer au collège et sur la bonne manière d'y parler)), art. 29 («O sekretarskom upravlenii » (Sur les fonctions de secrétaire)), art. 50 («O nagraždenii i štrafah » (Sur les récompenses et les amendes)).

10. Ibid. Règlement général de 1720, art. 4 («Ob ispolnenii ukazov » (Sur l'exécution des oukases)), art. 25 (« Nadziranie na postupki služitelej» (Sur la surveillance de la conduite des commis)), art. 26 ( O respekte, nadležaščem presidentam » (Sur le respect dû aux présidents)), art. 54 («O kolležskih služiteljah, čtob vyšnim svoim poslušanie činili » (Sur les commis des collèges, afin qu'ils montrent de l'obéissance envers leurs supérieurs)).

11. Ibid., p. 378. Oukase du 19 décembre 1718 («Ukaz kak čelobitčikam postupat’ nadležit » (Oukase sur les comportements à adopter envers les solliciteurs)).

12. À ce propos, voir E. V. Anisimov, Gosudarstvennye preobrazovanija i samoderžavie Petra Velikogo v pervoj četverti XVIII veka (Les réformes administratives et le pouvoir autocratique de Pierre le Grand durant le premier quart du XVIII siècle), Saint-Pétersbourg, Dmitrij Bulanin, 1997, p. 170-173.

13. Henningue Frédéric de Bassewitz, Zapiski o Rossii pri Petre Velikom (Mémoires sur la Russie du règne de Pierre le Grand), Moscou, 1866, p. 123. 
Bergholz, comprenaient les questions suivantes : «1) Qui es-tu ?2) Qui t'a désigné à cette charge ? 3) As-tu détourné les deniers publics ? 4) As-tu déjà été puni par le fouet ou autrement? », etc. Dans leur intérêt, les commis avaient à répondre « l'unique vérité » car, même s'ils étaient reconnus coupables, ils pouvaient néanmoins espérer la grâce du tsar ${ }^{14}$.

Quoi qu'il en soit, la législation pétrovienne qualifia le détournement des deniers publics, la corruption et la violation des oukases de crimes d'État (gosudarstvennye prestuplenija) ${ }^{15}$. La jurisprudence de cette époque traita chacune de ces fautes avec une extrême rigueur ${ }^{16}$. Ces abus étaient criminels, tant dans le sens juridique proprement dit que matériellement et financièrement, puisqu'ils causaient « des dégâts et des dommages à l'État (gosudarstvo) » ${ }^{17}$. « Comme tout mal tire son origine de la cupidité », le tsar appela les administrateurs à «se retenir de toute concussion » et « à se contenter de ce qui est donné », car «beaucoup d'intérêts de l'État (gosudarstvennye interesy) sont souvent perdus par la faute de ce mal ${ }^{18}$. Le gaspillage des deniers publics et les pots-de-vin apparurent dans les oukases sous les termes «d'acquisitions malicieuses », « de vol des intérêts de l'État » et « de friandises abjectes ». Les pots-de-vin étaient qualifiés d'odieux et d'infâmes, les commis corrompus de «voleurs des intérêts de l'État qui n'apprécient rien, mais détruisent peu à peu tout le bien et le mettent au service de leur avidité » et «ne peuvent être appelés que traîtres et ennemis de la Patrie ${ }^{19}$.

La lutte contre les malversations prit une forte valeur politique. En règle générale, il fut admis que si les administrateurs n'avaient pas une réputation irréprochable dans l'exercice de leurs devoirs, cela causerait «non seulement l'indiscipline de leurs subordonnés, mais aussi leur ruine et une tentation pour les juges, car quand on voit l'un s'enrichir indûment et impunément, on n'en trouve que très rarement d'autres qui n'en soient pas alléchés ». Les abus menant « au malheur et aux

14. Friedrich Wilhelm von Bergholz, Dnevnik kamer-junkera Bergholz (1721-1725) (Journal du kammer-junker Bergholz, tenu de 1721 à 1725), Moscou, 1902-1903, p. 154-155.

15. PSZ, t. 7, n 4460. Oukase du 5 février 1724 («O različii štrafov i nakazanij za gosudarstvennye prestuplenija » (Sur les diverses amendes et peines encourues pour les crimes d'État)).

16. Les aspects juridiques de l'histoire de la corruption en Russie auX XVII et XVIII ${ }^{\mathrm{e}}$ siècles sont abordés par K. Ančiferov, «Vzjatočničestvo v istorii russkogo zakonodatel'stva » (La corruption dans l'histoire de la législation russe), Žurnal graždanskogo i ugolovnogo prava, 2, 1884, p. 3-48; P. Sedov, « Na posule kak na stule. Iz istorii rossijskogo činovničestva XVII veka » (Chose promise, chose due. La corruption: points d'histoire de la bureaucratie russe au XVII siècle), Zvezda, 4, 1998, p. 205-214 ; V. N. Čirjaev, Vzjatočničestvo i lihoimstvo v svjazi $s$ obščim učeniem o dolžnostnyh prestuplenijah. Ugolovno-juridičeskoe issledovanie (La corruption et la concussion dans la doctrine générale des crimes de fonction. Étude juridique et criminelle), Jaroslavl', 1916.

17. PSZ, t. 5, n 2871. Oukase du 24 décembre 1714 ( $O$ vospreščenii vzjatok i posulov $i$ o nakazanii za onoe » (Sur l'interdiction des pots-de-vin et des promesses de cadeaux, et sur les peines encourues)).

18. Ibid., t. 6, n 3586. Oukaze du 21 mai 1720 («O nakazanii za vzjatki i lihoimstvo » (Sur les punitions pour corruption et concussion)).

19. Ibid., t. 5, n² 2707. Oukaze du 25 août 1713 («O presečenii grabitel'stv V narodnyh sborah » (Sur l'élimination des exactions dans les prélèvements sur le peuple)). 
souffrances injustifiées des peuples et au préjudice de l'État », « ils [les administrateurs] ruineront peu à peu le pays, provoqueront la colère de Dieu et entraîneront ainsi le malheur et la chute finale de l'État $»^{20}$. Voilà pourquoi, tout au long de son règne, Pierre Irr attribua un rôle primordial à l'organisation du contrôle externe qui lui permettait de détecter et de détruire tous ces abus, au nom de «l'État», mot qu'il utilise fréquemment dans ses oukases.

\section{Le contrôle des finances a posteriori et a priori : organisation et missions}

Au début du XVIII ${ }^{\mathrm{e}}$ siècle, les services de contrôle étaient organisés par le Sénat selon des principes territorial et fonctionnel. Cette tutelle de l'administration sur les contrôleurs leur imprime une particularité immédiate. En effet, le Sénat n'exerçait pas uniquement le pouvoir exécutif, mais aussi la fonction de contrôle liée à ce pouvoir. Cette tâche, tout aussi importante que ses autres compétences, faisait de lui le centre stratégique du gouvernement du pays. Le contrôle renforçait le pouvoir monarchique en lui permettant de mieux administrer, de centraliser la gestion des finances et de les contrôler de manière plus efficace.

Héritière du Bureau des comptes (Sčetnyj prikaz), la Chancellerie intime (Bližnjaja kanceljarija) participait au contrôle financier a posteriori. Elle étendait son ressort sur tout le territoire du pays et arrêtait les comptes des institutions centrales à la fin de l'année courante. Entre 1711 et 1714, ce travail fut repris par le Sénat parallèlement à la Chancellerie intime. L'établissement des collèges, en 1717-1719, et en particulier des trois collèges dans les finances, annonça la centralisation de la gestion financière et la nouvelle réorganisation du contrôle. L'examen des comptes et la recherche des abus fiscaux appartinrent désormais au collège de Révision des comptes (Revizion-kollegija) placé sous la surveillance générale du Sénat. À partir de 1722, le collège devint un service du Sénat (Revizion-kontora) sous la direction de l'ober-prokuror Ivan Bibikov. Ce nouveau type de contrôle financier élaboré sur la base de différentes modifications institutionnelles était lié au contexte politique et financier complexe du moment. En effet, la réforme administrative influa sur l'exercice du contrôle d'autant plus que le pouvoir chercha constamment à optimiser son efficacité. Malgré une réglementation assez stricte en matière de délais, les comptables tardaient, d'une année à l'autre, à présenter leurs comptes. Leur contrôle était de plus en plus ralenti par le jugement des comptes lui-même, lorsque les services de contrôle clôturaient en une seule fois des comptes de plusieurs années antérieures : ainsi, en 1714, la Chancellerie intime vérifia les comptes non arrêtés au Sénat en 1712-1713 ; à son tour, le collège de Révision des comptes continua d'examiner les comptes présentés à la Chancellerie intime en 1714-1715. Il n'est donc pas étonnant qu'une grande quantité de registres des finances se soit accumulée dans leurs bureaux et que le contrôle ait pris plutôt le caractère de simple reddition des comptes 
que de véritables vérifications. En réalité, la Chancellerie intime ne procédait que rarement à un examen approfondi de la gestion comptable. Ces conditions difficiles poussèrent la monarchie russe à chercher d'autres modes d'exercice du contrôle ; elle eut recours à des instances de contrôle a priori.

Par les oukases du 5 mars 1711 et du 14 mars 171421, Pierre le Grand mit en place les structures centrales et locales des procureurs fiscaux (fiskaly) en les chargeant d'exercer simultanément et en continuité le contrôle financier et administratif 22 . Le chef des procureurs fiscaux - l'ober-fiskal - siégeait auprès du Sénat et était aidé de quatre adjoints ${ }^{23}$. Deux d'entre eux devaient être nommés parmi les marchands, « afin de veiller plus particulièrement à ce corps », les autres étant issus de la noblesse. Dans le reste du pays, on trouvait les procureurs fiscaux provinciaux, accompagnés de leurs commis. Il y avait également des procureurs fiscaux urbains à raison d'un ou deux par ville ${ }^{24}$. D'ailleurs, ces proportions arithmétiques n'étaient pas toujours respectées ${ }^{25}$; la subordination directe des procureurs fiscaux

21. N. A. Voskresenskij, op. cit., p. 204, 233-234.

22. Sauf rares exceptions, l'historiographie ne propose pas d'étude particulière des procureurs fiscaux en Russie. Le sujet reste davantage présent dans les ouvrages consacrés à l'histoire du Sénat et du Parquet, voir T. V. Barsov, «O svetskih fiskalah i duhovnyh inkvizitorah » (Les procureurs fiscaux civils et ecclésiastiques), Žurnal Ministerstva narodnogo prosveščenija, 2, 1878, p. 321-400 ; Istorija Pravitel'stvujuščego Senata za 200 let (1711-1911) (Deux cents ans d'histoire du Sénat gouvernant (1711-1911)), Saint-Pétersbourg, 1911, p. 245-375 ; A. Gradovskij, Vysšaja administracija Rossii XVIII stoletija i general-prokurory (La haute bureaucratie et les procureurs généraux dans la Russie du XVIII siècle), Saint-Pétersbourg, 1866; S. O. Petrovskij, O Senate v carstvovanie Petra Velikogo (Le Sénat sous le règne de Pierre le Grand), Moscou, 1875; N. Murav'ev, Prokurorskij nadzor v ego ustrojstve i dejatel'nosti (Le Parquet russe : son organisation et ses activités), Moscou, 1889 ; A. Stepanov, «O formah pravitel'stvujuščego nadzora v Rossii v XVIII veke » (Les formes du contrôle d'État en Russie au XVIII' siècle), Universitetskie izvestija (Kiev), 6-7, 1867 ; M. Polievktov, Proekt barona Gjujsena ob učreždenii $v$ Rossii fiskal-kollegii (Le projet du baron Hüyssen pour la création du collège des procureurs fiscaux en Russie), Saint-Pétersbourg, 1914.

23. L'ober-fiskal pouvait être nommé par le tsar lui-même (comme le panetier Jakob Bylinskij, le procureur fiscal Aleksej Nesterov et le colonel Aleksej Mjakinin) et pouvait être choisi parmi les candidats proposés par le Sénat (le panetier Mihail Željabužskij et le procureur fiscal Mihail Kosoj). Aleksej Nesterov fut une figure remarquable de l'histoire du contrôle russe. D'origine roturière, il commença son service en 1704 comme receveur d'impôts sur la pelleterie et devint procureur fiscal en 1712. Ses activités infatigables de contrôleur lui procurèrent une carrière brillante : il obtint un avancement en trois ans, passant de sa charge de procureur fiscal à celle qui lui était supérieure (ober-fiskal).

24. Sur la composition sociale du corps des procureurs fiscaux, voir G. Anpilogov, « Fiskalitet pri Petre I » (Les procureurs fiscaux sous Pierre Ir), Vestnik MGU, Istoriko-filologičeskaja serija, 2, 1956, p. 65-80; S. Šestakov, «Formirovanie instituta fiskalov v Rossii v pervoj treti XVIII veka » (La formation de l'institution des procureurs fiscaux en Russie dans le premier tiers du XVIII siècle), in I. A. Bulygin, ed., Reformy v Rossii XVI-XIX vekah (Les réformes en Russie, $X V I^{\mathrm{e}}$-XIXe s.), Moscou, 1992.

25. Les procureurs fiscaux dans les provinces ne disposaient jamais des quatre commis prévus, mais d'un ou de deux seulement. Leur nombre mis en place était inégalement réparti à travers le pays. Les gouvernements de Moscou, de Saint-Pétersbourg, d'Astrakhan et de Kiev avaient un seul procureur fiscal. Dans certaines villes, on trouvait trois, ou plus, procureurs fiscaux, comme à Koursk, à Tourinsk, à Orel et à Simbirsk. Parfois, deux ou plusieurs villes étaient regroupées sous la compétence d'un seul procureur fiscal : ainsi, Mihail Mokasov s'occupait à la fois des villes de Kozel'sk et de Moščevsk. Pierre Ier interdit sévèrement aux nobles âgés de moins 40 ans et aux marchands du premier degré d'entrer dans cette fonction. 
des provinces et des villes à leur supérieur n'était pas toujours très marquée ${ }^{26}$, ce qui handicapa l'efficacité de leur tâche.

Sans entrer dans tous les rebondissements de l'évolution des procureurs fiscaux en Russie, il convient de remarquer que le contrôle a priori fut une réelle nouveauté, tant pour le système administratif que par rapport à l'ancienne organisation du contrôle. L'introduction d'un contrôle des finances de type nouveau, une des plus importantes réformes de Pierre le Grand, ne pouvait se faire sans l'adaptation au cas russe de l'expérience étrangère. Des éléments prussiens, suédois et français se combinèrent dans son organisation. Le système des procureurs fiscaux développé localement dès 1711, d'après le modèle suédois, fut complété par l'emprunt à l'expérience française de l'organisation du Parquet ${ }^{27}$. Ainsi s'exprimait la volonté de Pierre I ${ }^{\mathrm{er}}$ de contrôler tout son appareil de décision et d'administration, de haut en bas. Cette démarche fut à l'origine d'un système de contrôle original, sans analogue européen. Dans les faits, les archives ne laissent que peu de traces de la réelle collaboration des deux instances. En fait, le Parquet ${ }^{28}$ concentra très vite entre ses mains la totalité du contrôle, et les procureurs fiscaux furent supprimés en vertu de l'oukase du 29 décembre 172929.

\section{L'effort du contrôle dans le domaine fiscal}

Les difficultés financières conduisirent la monarchie russe à abandonner l'ancienne fiscalité directe. En 1724, divers impôts directs furent remplacés par un impôt

26. L'oukase du 17 mars 1714 plaça les procureurs fiscaux en double dépendance institutionnelle. D'une part, ils obéissaient aux ordres de leur supérieur hiérarchique, l'ober-fiskal, et, d'autre part, ils étaient soumis à l'autorité des gouverneurs et ce, dans la mesure où ceux-ci n'abusaient pas de leurs devoirs.

27. En France, les premiers procureurs et avocats du roi furent nommés par l'ordonnance de Philippe le Bel du 15 mars 1303. Au tribunal, ils siégeaient à part, sur la même estrade que les juges, dans l'un des petits parcs appelés parquets, où ils se réunissaient pour délibérer des affaires qui regardaient les intérêts du roi. Par convenance de langage, dès le XVII siècle, le mot parquet utilisé pour désigner la chambre séparée et réservée au procureur général, assisté d'un certain nombre d'avocats généraux et de substituts, finit par désigner de manière précise les gens du roi eux-mêmes. Le terme «parquet » ne correspond alors absolument pas au synonyme de plancher d'une salle d'audience, comme cela a pu être soutenu à tort. Cette nouvelle acception sémantique conduisit peu à peu ce terme à son sens juridique actuel. Les compétences des gens du Parquet eurent tendance à s'accroître au cours des siècles. Au début du XVIII siècle, outre le rôle qu'ils jouaient auprès des juridictions pour défendre les intérêts du roi, les procureurs avaient mission d'appeler à la discipline dans les parlements et les cours royales, de veiller à l'application des arrêts et règlements et d'assurer l'ordre et la sécurité publics dans tout le royaume. Chaque fois que l'intérêt public et les droits du monarque leur paraissaient menacés, les procureurs devaient provoquer l'intervention de leur juridiction en prenant des réquisitions et en déposant des conclusions. Le procureur général communiquait des édits et déclarations du roi à l'enregistrement au Parlement de Paris (R. Albernhe, Le Ministère public, Paris, 1988 ; Jean-Marie Carbasse, ed., Histoire du Parquet, Paris, PUF, 2000).

28. L'établissement du Parquet en Russie fut l'objet d'une remarquable étude de V. Veretennikov, Očerki istorii general-prokuratury v Rossii doekaterininskogo vremeni (Essais sur l'histoire du Parquet en Russie avant le règne de Catherine II), Kharkov, 1915.

29. PSZ, t. $8, \mathrm{n}^{\circ} 5431$. 
principal : la capitation (podušnaja podat', littéralement « l'impôt sur les âmes »). Visant à accélérer les rentrées fiscales, cette unification améliora également le contrôle financier, dont l'efficacité se heurtait à la multiplication des impositions et à un grand désordre dans leur répartition et leur collecte, confiées à plusieurs administrations.

Le recensement de la population roturière masculine et sa vérification amorcèrent la réforme fiscale. Ces opérations n'avançaient qu'avec des difficultés dues à de fortes oppositions de la population et à un important « recel des âmes » (utajka duš). Le gouvernement parvint à maîtriser la situation et obtint, par une meilleure coordination des actions des réviseurs, des dénonciateurs et des services de contrôle, un total de 5,5 millions de personnes recensées ${ }^{30}$. Le nouvel impôt fut fixé à 74 kopecks par âme pour les paysans et à 80 kopecks par âme pour le corps des métiers (posadskie ljudi) ; les imposés devaient verser leurs payements au commissaire provincial (zemskij komissar) tous les quatre mois. La recette fiscale était mise immédiatement à la disposition des armées russes cantonnées dans les gouvernements, résolvant ainsi les problèmes financiers liés à leur maintien en période de paix. Cette opération évita le transfert des fonds et leur longue redistribution par la caisse centrale, d'autant plus qu'elle assurait le recouvrement de l'impôt et des arrérages plus rapidement et en respectant les échéances. Enfin, la fonction policière de l'armée répondit aux besoins d'améliorer le contrôle de l'administration des finances. Celle-ci était surveillée directement et sur place. En présence du colonel, les officiers de chaque régiment réunis procédaient à l'élection de ceux d'entre eux qui étaient chargés d'accompagner le commissaire provincial dans son voyage dans les campagnes et de recouvrer collectivement l'impôt ; lors de la perception, «pour que le commissaire provincial ne commette aucune prévarication $»^{31}$, ils veillaient à ce que celui-ci tienne correctement le registre des recettes, en indiquant les dates, les noms des contribuables et le montant des sommes versées. Ces commis portaient l'entière responsabilité, mutuelle et pécuniaire, de l'état du recouvrement. Le commandant du régiment se tenait au courant de l'ensemble des opérations financières et surveillait la conduite des comptables. En accord avec les gouverneurs, il pouvait engager des poursuites à l'encontre des commissaires provinciaux et les révoquer en cas d'abus. Les commissaires provinciaux, quant à eux, versaient les fonds au receveur du régiment qui inscrivait alors leur montant sur son registre de recettes tandis que le commandant visait le registre de dépenses du commissaire provincial. Plus tard, une partie des rentrées fiscales fut envoyée au collège de la Guerre, tandis que l'autre était laissée dans les caisses locales. Un officier préposé à leur maniement rendait compte de ses opérations par trimestre et à la fin de l'année devant la réunion de son régiment et au collège de la Guerre. Le colonel du régiment jouait un rôle d'arbitre et réglait tout le contentieux entre l'armée et les habi$\operatorname{tants}^{32}$. À partir de 1719, les receveurs (kamerir) surveillaient, auprès des gouver-

30. E. V. Anisimov, Podatnaja reforma Petra I, op. cit., p. 90.

31. PSZ, t. 7, n 4328 . Oukase du 18 octobre 1723.

32. Ibid., t. 7, n 4294. Oukase du 3 septembre 1723. 
neurs, l'exactitude de la comptabilité locale : ils vérifiaient tous les mois les registres des commissaires provinciaux et envoyaient leurs propres rapports trimestriels et annuels aux trois collèges des Finances.

La fin du XVII siècle et le début du XVIII ${ }^{\mathrm{e}}$ siècle annoncèrent de grands changements dans le système des impôts indirects en Russie. Pour augmenter les recettes fiscales, Pierre Ier élargit le monopole de l'État sur certains produits et créa de nouvelles taxes : sur la production et la vente du tabac, de la potasse, du goudron, de la rhubarbe, de la colle de poisson et du caviar. Parmi les innovations, figuraient les droits sur les bains et les cheminées, sur les forges et les charretiers, sur la production du kwas et du vinaigre, de la cire et des cierges, du savon et des cuirs. Des taxes étaient levées sur les baptêmes, les mariages et les sépultures. Le droit sur les actes ( « le papier timbré ») fut établi en 1699. Le fameux oukase sur la coupe des barbes et des moustaches apparut en 1705. Les «droits des bureaux» (kanceljarskie sbory) donnèrent au total 624627 roubles en 1724. Ces prélèvements étaient de même importance que l'impôt sur le sel (606 982 roubles), les droits sur les boissons (850 105 roubles) et sur le tabac (42 391 roubles). Dans l'ensemble, les taxes indirectes représentèrent $25 \%$ des ressources fiscales de la monarchie russe ${ }^{33}$.

Pour couvrir les besoins financiers de la guerre, le monopole monarchique sur la vente du sel fut établi en 1705 sur tout le territoire du pays ${ }^{34}$. C'était, par excellence, un expédient fiscal de bon rendement : le sel étant une denrée de consommation universelle et le principal moyen de conservation de quantités de produits, le pouvoir pouvait facilement en tirer une ressource considérable. Les salines et le recouvrement des droits furent administrés d'abord par le Bureau des bénéfices (Pomestnyj prikaz) puis, à partir de 1720, par le collège des Recettes. Sous leur direction et surveillance, des greniers à sel furent créés dans chaque gouvernement. Leur personnel (soljanye burmistry, golovy et celoval'niki) assurait le transport et la conservation du sel dans les greniers et le vendait dans les magasins publics.

L'établissement du monopole ne mit cependant pas fin au saunage des particuliers. Bien que l'extraction et la fourniture du sel aient été affermées à des marchands entrepreneurs, l'État protégeait et développait sa propre production. Pour garantir la rentabilité de ses salines, l'oukase de 1724 réglementa le saunage des particuliers par l'institution d'une norme de production annuelle de sel et pénalisa la surproduction. Soucieux d'une fourniture de sel régulière, le gouvernement augmentait de temps en temps les prix fixés dans les baux. Les producteurs bénéficiaient du droit d'exploitation de certaines salines et d'exemptions fiscales, tout en ayant le soutien des autorités sous forme de subsides et de main-d'œuvre. En contrepartie, par diverses interventions ponctuelles et constantes, le pouvoir exigea qu'ils produisent un sel de bonne qualité.

33. S. M. Troickij, op. cit., p. 192.

34. PSZ, t. 4, n² 2009. Oukase du 1er janvier 1705 ( O prodaže soli iz kazny $i$ stat i o postavke onoj podrjadom » (Sur la vente du sel par le Trésor et les articles sur la fourniture à forfait du sel). 
La perception des droits sur les boissons (kabackie sbory) fut centralisée dans la Burmisterskaja palata puis au collège des Recettes. Le monopole de l'État fut étendu à la production, la fourniture et la vente des boissons. L'oukase du 9 février 1710 défendit aux particuliers de produire des boissons et les obligea à les acheter dans des magasins publics. Mais cette décision fut bientôt abandonnée. En 1716, les propriétaires fonciers furent autorisés à produire des boissons pour leur propre usage, à condition de payer une taxe. Ils pouvaient affermer leur production et leur fourniture dans les débits de boissons publics, de même que les marchands et les corps de métiers, à l'exception des paysans. Les bureaux centraux réglaient les conditions des baux tandis que les candidats (otkupščiki) présentaient des cautions (poručnye zapisi). Les producteurs pouvaient fournir la boisson déjà prête ou ce qui était nécessaire à sa confection. Les grains et le houblon étant fournis, leur prix et les lieux d'achat furent obligatoirement inscrits par les commis sur les registres de recettes des bureaux de vente (kabackie golovy et celoval'niki). Pour vérifier la qualité des boissons, les particuliers envoyaient également aux autorités centrales des échantillons de leurs produits, scellés et signés. Les boissons provenant des distilleries privées ne pouvaient être vendues que par l'État. Il en résulta une fraude (tajnoe vinokurenie) qui devint intense et porta un grand préjudice aux intérêts du monarque.

Par des prescriptions spéciales, le tsar demanda aux procureurs fiscaux de veiller au monopole sur les boissons. Les archives russes en donnent plusieurs exemples. En 1715, les procureurs fiscaux Menšov et Sanin signalèrent que le kabackij golova de Iaroslavl, Smoljaninov, avait détourné 50 roubles de sa caisse. Le Sénat le condamna à la restitution de la somme et récompensa les procureurs fiscaux de 25 roubles $^{35}$. Les commis de Mozajsk furent poursuivis pour mauvaise conservation et mauvaise qualité des boissons en $1724^{36}$. Dénoncée par le procureur fiscal Šepelev pour la fabrication frauduleuse de boissons dans ses villages, la propriétaire foncière Vjazemskaja paya 75 roubles d'amende ${ }^{37}$. Près de Moscou, les nobles Somov et Prončiščev produisirent des eaux-de-vie à usage personnel sans en payer la taxe. Le payement fut recouvré pour chaque unité de mesure, dont la moitié revint aux procureurs fiscaux ${ }^{38}$. Le zemskij komissar Sergeev et l'oberfiskal Nesterov firent des rapports sur la mauvaise administration des distilleries officielles confiées au prince Aleksandr Menšikov et au général Pomeranskij. Ceux-ci tardaient à fournir 100000 seaux de boissons à Saint-Pétersbourg. Menšikov n'avait envoyé aucun compte sur la quantité produite ni sur les sommes perçues lors de sa vente. Pour répondre, le prince écrivit directement à Pierre Ire et,

35. RGADA (Rossijskij gosudarstvennyj arhiv drevnyh aktov - Archives des actes anciens de l'État de Russie), f. 386 (Kanceljarija fiskal'skih del (Bureau des affaires fiscales)), op. 1, d. 2, 1.232 .

36. Ibid., f. 386, op. 1, d. 9.

37. Ibid., f. 248 (Pravitel'stvujuščij Senat (Sénat gouvernant)), op. 106, d. 5, 1. 239.

38. Ibid., f. 248, op. 106, d. 5, 1. 158-160. 
en réfutant les accusations, invita le tsar à ne pas croire ses dénonciateurs. Entretemps, il ordonna à sa garde de maintenir le commissaire Sergeev en détention ${ }^{39}$.

La monarchie russe exerça pleinement son droit de contrôle sur l'ensemble des services employés à la levée des droits indirects. Le contrôle financier fut soigneusement hiérarchisé. Les gouverneurs devaient veiller à ce que les commis perçoivent les droits sans délais et en dehors de tout intérêt personnel, favoritisme ou potsde-vin ${ }^{40}$. La remise des recettes fiscales s'effectuait en leur présence. Comme les commis dépensaient assez souvent une partie des fonds pour les besoins de leurs services, les gouverneurs procédaient à la vérification des registres de dépenses et des pièces correspondantes. Les commis reçurent l'ordre de réduire leurs dépenses d'une année à l'autre et de ne pas vendre les boissons en acceptant une caution. Pendant la vente des boissons, ils ne devaient accepter que les payements en espèces, de même qu'en 1696, les acheteurs obtinrent le droit de mesurer euxmêmes la quantité de boissons qu'ils achetaient ${ }^{41}$. Les fonds perçus étaient déposés par les commis dans des coffres métalliques. L'oukase du 30 août 1698 obligea les celoval'niki «à examiner tous les coffres pour que leurs couvercles scellés ne bougent pas et que des pièces n'en tombent pas, pour que leurs adjoints ne volent pas d'argent en perçant des trous dans les coffres $»^{42}$. Les gouverneurs désignaient celui des secrétaires qui devait noter sur son registre les rentrées fiscales et les fonds expédiés au Trésor public. En examinant la comptabilité locale, ils adressaient leurs états mensuels, trimestriels et annuels récapitulant les recettes et les dépenses de leurs provinces au collège des Recettes, au collège du Commerce et au collège de Révision des comptes, qui exerçaient la surveillance générale sur l'ensemble des services gouvernementaux.

\section{Les procédures de contrôle financier}

Lorsque les opérations de perception des deniers publics et le détail de l'emploi qui en était fait figuraient sur la comptabilité de chaque commis, la vérification de l'authenticité et de l'exactitude de ces inscriptions formait un bon outil de contrôle ${ }^{43}$. Pour faciliter l'examen des comptes, le gouvernement normalisa la

39. Ibid., f. 248 , op. 5 , kn. 272 , d. $26,1.933-940$.

40. PSZ, t. $5, n^{\circ} 3294$. Instruction aux gouverneurs du $1^{\text {er janvier }} 1719$ (art. 24, 25, 26).

41. Ibid., t. 3, n 1548. Nakaz Vsesvjatskogo kamennogo mosta golove gostinnoj sotni Ivanu Vihljaevu dlja sbora denežnoj kazny ot pitejnoj prodaži i drugih pošlin (Instruction à Ivan Vihljaev chef de la corporation des marchands de Vsesvjatskij Kamennyj most concernant la collecte des droits sur la vente des boissons et autres taxes), du 1 ${ }^{\text {er }}$ septembre 1696.

42. Ibid., t. 3, n 1642. Nakaz gostju Kirille Lobaznovu o sbore denežnoj kazny na Moskovskom otdatočnom dvore (Instruction au négociant Kirill Lobaznov concernant la collecte des droits sur la vente des boissons dans le otdatočnyj dvor de Moscou), du 30 août 1698.

43. Dans cette optique, rappelons que le sens initial du «contrôle » était «contre-rolle » : il s'agissait de vérifier si les inscriptions comptables portées sur un registre des finances concordaient avec celles d'un registre servant de référence. 
tenue des registres des finances. Les comptables étaient invités à suivre les règles de comptabilité définies par le Règlement général de 1720 et précisées par le Règlement de 1'Amirauté44. Dans leurs registres reliés, numérotés et signés sur la première et la dernière feuille, ils devaient mentionner, selon les articles, la date, le nom et la partie qu'ils versaient, le montant de la somme, la cause du paiement et la nature des valeurs employées. Pour toutes les opérations financières, il fallait distinguer deux registres, l'un destiné à la recette et l'autre à la dépense. Le collège de Révision des comptes reçut l'ordre de faire appliquer à travers le pays les nouvelles règles comptables aux deniers publics, tant en argent qu'en vivres.

Le souci d'établir un bon ordre dans la comptabilité se traduisit par l'obligation des comptables d'exercer la collecte en conformité avec les oukases et les tarifs décidés par le pouvoir, sous peine d'amendes et de punitions corporelles. Une grande attention fut accordée non seulement aux modes de payement des dépenses, mais surtout à leur ordonnancement. Le tsar ordonnait des dépenses comme il le jugeait nécessaire. Les oukases pour les dépenses étaient préparés à l'avance dans son Cabinet et au Sénat, pour être soumis à sa signature, puis étaient transmis pour exécution aux collèges et aux gouverneurs. Le collège des Dépenses répondait entièrement des payements et de leur contrôle dans le pays. Chaque année, d'un commun accord avec le collège des Recettes, il établissait un état prévisionnel des dépenses et y mentionnait, par chapitre, les plus importantes, celles de la cour, des armées et de la marine et celles de l'appareil administratif. Ce document était présenté au Sénat et arrêté par le tsar. Ensuite, aucune dépense ne pouvait être proposée sans l'autorisation du tsar et sans en informer les trois collèges des Finances.

Une série de précautions et de garanties d'ordre administratif fut imposée aux comptables. Elle complétait la fonction de contrôle. Pour remplir les charges des collecteurs d'impôts, on chercha «des personnes de bonne qualité ». On exigea qu'elles sachent lire et écrire et qu'elles soient solvables, car leur nomination même à cette charge engageait tous leurs biens meubles et immeubles. La plupart des impositions indirectes étaient recouvrées par les commis qui étaient élus chaque année par les habitants de leurs circonscriptions. L'oukase portant règlement de cette procédure prescrivit que les marchands, les paysans et le corps des métiers procèdent à leur élection suivant « la bonne raison et non pas par amitié, sans injure, sans pression et sans influence des plus riches, mais en tenant compte de leur vertu et de leur vie chrétienne $\gg^{45}$. Les participants signaient les procès-verbaux à la fin de la procédure. Dès leur entrée en fonction, les nouveaux candidats examinaient l'état des recettes de leurs prédécesseurs et dressaient collectivement les rôles. Ensuite, ils s'engageaient sous serment à remplir fidèlement leur charge. Le serment servait ainsi à prévenir leurs éventuelles malversations par l'énumération extrêmement précise de leurs devoirs. Les commis des distilleries publiques s'engageaient à ne pas « se nourrir » de la recette de l'impôt; à ne pas faire leurs

44. PSZ, t. 6, n 3937. Articles 31,32,36, 67 et annexes du Règlement de l'Amirauté.

45. D. Tolstoj, op. cit., p. 142. 
propres achats à titre gratuit dans les débits de boissons ; à ne pas remplacer les boissons publiques par une boisson produite par eux-mêmes ; à taxer dûment les « poivrots » (petuhi) et à ne pas les chasser hors du lieu de vente; à utiliser les mesures de contenance fixées par les oukases - les seaux, les bocks (kružki), les demi-bocks (polu-kružki) et les godets (čarki) — sans les altérer ; à acheter directement les provisions et à ne pas diminuer leur prix sur les registres; à ne pas employer de l'argent public pour leurs dépenses ; à n'imposer à personne des taxes indues ; enfin, étant présents à la perception des droits, à surveiller le comportement de leurs subordonnés pour « qu'ils soient toujours disponibles pour l'approvisionnement des débits de boissons, qu'ils soient zélés et non ivres, qu'ils ne profitent pas des deniers publics et ne les cachent pas derrière les coffres, qu'ils ne prennent pas trop d'argent aux buveurs et qu'ils remplissent à ras bord leurs godets, qu'ils ne vendent pas en secret à l'entrée et à la sortie des distilleries. ${ }^{46}$ Le serment avait donc pour effet de responsabiliser les commis.

L'analyse des pièces comptables destinées au contrôle a posteriori concernait trois sphères de vérification. La vérification générale comprenait le contrôle de l'ensemble des impôts sur la totalité de la période déterminée. La vérification simple ne concernait qu'un seul impôt. Enfin, la vérification particulière était réalisée sous forme d'examen de la perception de tel ou tel impôt sur une période restreinte en cas de fraude établie. La documentation financière fournie pour la reddition des comptes différait de celle des services du contrôle qui résultait des vérifications. Après avoir analysé différents registres et états comptables, la Chancellerie intime et le collège de Révision des comptes dressaient toute une série de tableaux et d'états généraux des recettes et des dépenses en mentionnant, pour chaque type d'impôt, les restes ou le surplus, les nouvelles dépenses, en comparaison avec celles des années précédentes, etc. De cette façon, le gouvernement pouvait mieux évaluer les revenus disponibles et mieux suivre le mouvement des fonds destinés à payer les dépenses extraordinaires.

La décision des instances du contrôle se traduisait par des arrêts portant sur les comptes examinés. Ces jugements concernaient uniquement la situation des comptables et non pas le contrôle de l'ordonnancement. En effet, les vérificateurs ne pouvaient apprécier que la procédure d'ordonnancement et non la qualité de l'ordonnateur, car la décision d'effectuer le recouvrement d'une recette ou le payement d'une dépense venait du monarque en personne. Ils n'étaient donc pas en droit de juger son comportement, même quand le monarque poussait les comptables à recouvrer des sommes indues ou à payer des dépenses non prévues. On ne devait examiner, à cette occasion, que la rectitude de l'exercice financier des comptables. Les agents de contrôle pouvaient leur donner une décharge pour les exercices jugés ou les menacer de poursuites lorsque des irrégularités étaient détectées dans les articles de recettes et de dépenses. Entre les deux, se posait le problème des articles dont les opérations mentionnées n'étaient pas accompagnées d'une pièce justificative. En 1714, la Chancellerie intime établit par exemple que les registres de 1710 
du Bureau des guerres et du Bureau de l'artillerie avaient respectivement 2928 et 196 parties «non indiquées » (nezamečennye mesta). La vérification des comptes des autres institutions centrales permit de découvrir au total 6924 pièces manquantes. Ces chiffres furent immédiatement communiqués au Sénat qui ouvrit une enquête spéciale à l'encontre des comptables soupçonnés ${ }^{47}$.

Le contrôle sur pièce donnait généralement lieu à la découverte de deux types d'erreurs. Le premier était dû à de mauvais calculs résultant de fautes d'inattention du commis pendant les écritures des comptes. C'était donc une erreur implicite et non intentionnelle (opiski), à la différence du second type d'erreurs produites explicitement et intentionnellement au détriment des intérêts de l'État. De nombreuses erreurs étaient détectées dans les comptes des dépenses. Elles figuraient sous forme d'inscriptions de dépenses qui n'étaient pas autorisées ni contenues dans les états estimatifs. Les dépenses fictives utilisant de fausses pièces formaient une autre forme de fraude. Quant à la recette, les registres étaient établis avec beaucoup de négligence : les comptables se trompaient de ligne et faisaient des fautes d'écritures. Souvent, ils ne délivraient pas de quittances après l'encaissement ou ils ne réclamaient pas les versements faits par certains contribuables. Il arrivait que le versement des arriérés, qui étaient reportés à diverses années, figurait dans des registres distincts et pouvait être recouvré deux fois. Aux inexactitudes dans les écritures, s'ajoutaient diverses omissions de recettes et la rétention des deniers. Cette pratique touchait presque tous les niveaux de l'administration, allant des petits commis provinciaux à de proches collaborateurs du tsar; ainsi en est-il des sénateurs Dolgorukij, Opuhtin, Musin-Puškin et du prince Menšikov, qui détournèrent de grosses sommes sous divers prétextes. Le vol d'argent public était si répandu en Russie que l'ambassadeur français Campredon annonça même que « les commis russes ne pensaient qu'à ruiner les sujets » et que « la lutte sévère de Pierre le Grand contre leurs prévarications serait inutile, car ni les confiscations ni les peines ne pouvaient changer le caractère des Russes qui, selon leur nature, étaient toujours disposés pour voler et mentir $»^{48}$.

Une autre infraction fréquente était la concussion. On retrouvait dans les comptes des articles corrigés (pripravočnye stat ${ }^{i}$ ) contenant des taxations plus élevées que celles auxquelles les commis avaient droit. Les commis extorquaient de l'argent et prenaient des pots-de-vin. Il arrivait qu'ils percevaient des droits selon les rôles des années précédentes et non pas selon ceux qui avaient été établis en dernier. La diminution des charges fiscales pendant la confection des rôles devint une véritable concussion pour les employés qui comptaient en tirer une gratifica-

47. Doklady i prigovory Pravitel'stvujuščego Senata (Rapports et arrêts du Sénat gouvernant), Saint-Pétersbourg, 1911, t. 4, kn. 2, n 1529. Arrêt du Sénat du 16 décembre 1714 (Prigovor o vysylke iz prikazov i kanceljarij d’jakov v Bližnjuju kanceljariju dlja otmetki pod stat'jami $v$ prihodnyh i rashodnyh knigah (Arrêt sur l'envoi des secrétaires des bureaux et des chancelleries à la Chancellerie intime pour l'enregistrement par articles dans les registres de recettes et de dépenses)).

48. Campredon, « Mémoire concernant les revenus du tsar dans toute l'étendue de ses États », in Sbornik Russkogo istoričeskogo obščestva, Saint-Pétersbourg, t. 40, p. 445. 
tion en la réalisant en faveur de leurs parents, d'amis et de ceux qui leur donnaient de l'argent à cet effet. On demandait aux commis des douanes (tamožennye burmistry et celoval'niki) de recouvrer chaque année des sommes supérieures à celles des années précédentes et on promettait des récompenses. Contrairement à ce qu'on attendait, cette disposition donna lieu à de fréquents abus. Soucieux d'augmenter les recettes, les commis prélevaient indûment des taxes plus élevées et installaient, sans aucune autorisation des autorités, de nouveaux bureaux de douanes. La perception des taxes à l'entrée et à la sortie des villes s'accompagnait de longues attentes. Les commis retenaient le plus longtemps possible les marchands pour vérifier leurs papiers, ce qui détériorait leurs marchandises.

Les instances de contrôle a posteriori reçurent une compétence de juridiction sur les commis préposés au maniement des fonds publics, d'où découla certainement la complexité du contrôle financier de l'époque moderne. Toutes les erreurs détectées dans les comptes étaient susceptibles de punition. Aux amendes et aux peines corporelles décrétées par la Chancellerie intime, s'ajoutaient, selon les oukases du 24 décembre 1714, du 10 février et du 22 juin 1720, la privation des charges et la saisie des biens des prévaricateurs et d'autres punitions, de l'envoi aux galères, aux travaux forcés jusqu'à la peine de mort. Ces peines s'étendaient aux commis euxmêmes et à leurs familles ${ }^{49}$.

La vérification des comptes n'était pas le seul mode de contrôle. Les activités administratives se trouvaient sous la surveillance constante des procureurs fiscaux. Ils exerçaient cette fonction différemment, d'une part, en personne et sur place, et d'autre part, à l'aide de leurs commis et collaborateurs bénévoles ${ }^{50}$. Leur présence, visible au quotidien, fit que les uns et les autres devinrent une crainte réelle pour chaque administrateur. L'idée d'être soumis au contrôle pouvait faire disparaître toute velléité de malversation, cette nouvelle méthode agissant positivement sur un plan psychologique.

En effet, le corps des procureurs fiscaux fut créé exclusivement pour la surveillance secrète. Sans pouvoir juger les crimes, ces procureurs ne faisaient que

49. PSZ, t. 5, $\mathrm{n}^{\circ} 2871$. Oukase du 24 décembre 1714 ( $O$ vospreščenii vzjatok i posulov io nakazanii za onoe » (Sur l'interdiction des pots-de-vin et des promesses de cadeaux, et sur les peines encourues)).; t. 6, n 3515. Oukase du 10 février 1720 («O nakazanii za izlišnie pobory »(Sur la peine encourue pour des exactions)); t. 6, $\mathrm{n}^{\circ} 3601$. Oukase du 22 juin 1720 ( $O$ raznyh gosudarstvennyh sborah i o nakazanii hiščnikov za vzjatki » (Sur les divers prélèvements d'État et sur les peines encourues par les déprédateurs pour les potsde-vin).

50. On a pris depuis longtemps l'habitude d'appréhender le contrôle comme l'action de vérifier et de corriger. En revanche, la notion de surveillance est comprise différemment. Cela est dû en partie à l'usage incorrect de ce mot dans la vie courante tant dans les époques éloignées qu'à présent. Dans le droit administratif, la notion est utilisée de préférence pour définir l'action de subordination entre des institutions de différents niveaux. La surveillance correspond à un acte d'autorité des supérieurs hiérarchiques vis-à-vis de leurs subordonnés, visant à diriger et à corriger leurs activités. Le terme de surveillance peut être également le synonyme de contrôle. Il définit alors une forme particulière de son exercice qui exclut de son champ l'action d'agir en vue de vérifier et de corriger et qui s'exerce uniquement dans le but d'observer et de rapporter sans intervenir. 
surveiller et rapporter au Sénat ${ }^{51}$. Même si l'oukase du 17 mars 1714 soumit la portée de leurs accusations à un délai de prescription, qui ne les autorisa plus à s'informer que contre ceux dont les abus étaient survenus avant l'année 1700, leur pratique excéda largement les limites qui leur avaient été imposées ${ }^{52}$.

Pour mener à bien leur travail de surveillance secrète, ils furent autorisés à pratiquer un contrôle ouvert : demandes d'informations, interrogatoires et confrontations, poursuites spontanées qui pouvaient aller jusqu'à des arrestations décidées de leur propre initiative. Par l'oukase du 27 novembre 1713, le Sénat insista sur la présence des procureurs fiscaux à la vente aux enchères du caviar restant après prélèvement pour la cour et l'exportation. Leurs rapports faisaient état d'un prix de vente au niveau le plus élevé53. Ils se tenaient toujours présents à la déclaration de diverses marchandises destinées à l'approvisionnement des armées et des institutions centrales en y procédant, avec les secrétaires et les officiers, à la confiscation des marchandises prohibées. Ce fut le cas en 1711 où les procureurs fiscaux de Moscou examinèrent 26 chariots de marchandises destinées au Bureau de Sibérie (Sibirskij prikaz). À la vérification des rôles, ils découvrirent qu'il n'y avait que 6 chariots chargés des denrées mentionnées, 20 chariots étant remplis de diverses « marchandises interdites » et non portées dans les inscriptions ${ }^{54}$. Celles-ci furent saisies en conséquence. Quant aux marchés publics, les procureurs fiscaux s'informaient des prix, des lieux de vente et de leur conformité aux règlements, et veillaient aux activités commerciales tant des marchands russes que des étrangers. En 1715, à la suite du rapport du procureur fiscal Obuhov, une partie des marchandises d'Iohann Smitt, habitant du faubourg «des Allemands» (Nemeckaja sloboda), fut confisquée par le Trésor public ${ }^{55}$. Les procureurs fiscaux faisaient continuellement état du non-respect de la législation sur le port de la barbe, non seulement de la part de la population, mais encore des administrateurs eux-mêmes, infraction constatée par exemple à Tver où le voïévode Labkov n'avait pas taxé les marchands barbus que le procureur fiscal Sidorov avait retenus sur les routes ${ }^{56}$.

Dans les premiers temps, les procureurs fiscaux n'avaient pas une représentation très claire de leur place auprès des instances judiciaires. Cela étant, dans le domaine de la justice, ils s'attribuèrent le rôle d'avocat privé dans les affaires litigieuses. L'affaire entre les particuliers Semen Anikiev et Ivan Semenov est significative de ce point de vue. En octobre 1712, à la mort de Fedor Ivanov, Semenov hérita non seulement de ses biens, mais aussi des dettes qu'il avait contractées auprès

51. N. A. Voskresenskij, op. cit., t. 1, p. 204. Oukase du 5 mars 1711 ( O rešenii del v Senate, o vybore ober-fiskala i ego dolžnosti » (Sur la procédure de prise de décision par le Sénat, sur l'élection de l'ober-fiskal et sur sa fonction).

52. Ibid., p. 334 . Oukase du 17 mars 1714 («Ukaz o fiskalah, ih dolžnosti i dejstvij » (Oukase sur les procureurs fiscaux, leur fonction et leur compétence).

53. Doklady i prigovory Pravitel'stvujuščego Senata, op. cit., t. 3, kn. 2, nº 1108 ; RGADA, f. 386 , op. 1, d. 7,18 .

54. RGADA, f. 248 , op. 106, d. 287, 1. 98-104.

55. Ibid., f. 248, op. 106, d. 345,1. 5.

56. Ibid., f. 386, op. 1, d. 29. 
d'Anikiev. Pourtant, Semenov refusa le payement et chercha à se justifier. Le Sénat reconnut les dettes de Semenov et l'obligea à les régler ${ }^{57}$. En décembre, une nouvelle affaire fut examinée à la demande des procureurs fiscaux. Cette fois, ce fut sur la plainte des frères Fedor et Pavel Honeev contre Andrej Grekov. Les deux frères prétendaient que Grekov possédait illégalement des alleux fonciers dont ils avaient hérité près de Moscou, à Povadino et à Sohino. En vérité, ces terres lui avaient été vendues par la mère des frères Honeev, durant leur minorité. Du fait que la mère ne fut pas reconnue héritière des biens, Grekov fut débouté de ses prétentions en vertu de l'arrêt du Sénat ${ }^{58}$. Quoi qu'il en soit, la plaidoirie des procureurs fiscaux pour les affaires particulières prenait beaucoup de temps et les détournait de leurs tâches principales de contrôle. Sur ce point, l'ober-fiskal Željabužskij écrivit au Sénat: « Si cela continue, les vraies et hautes affaires de Sa Majesté seront négligées au profit de celles des particuliers. » L'oukase du 24 avril 1713 mit fin à toutes ces interventions ${ }^{59}$. Mais, bien que cette interdiction fût répétée par le texte du 17 mars 1714 menaçant les procureurs fiscaux d'une peine rigoureuse, la pratique réelle contrariait son application.

Les malversations et le vol d'argent public devinrent le terrain privilégié de l'investigation des procureurs fiscaux. On les trouvait dans les greniers à sel, les collèges et les bureaux locaux où ils surveillaient l'exécution des règlements et de l'ordre disciplinaire. En cas de prévarications, les procureurs fiscaux disposaient d'une autorisation spéciale pour dépouiller les papiers dans les bureaux mêmes. En mai 1716 , le procureur fiscal Obuhov fit un rapport au Sénat sur la mauvaise conduite d'Ivan Ulanov, secrétaire du Bureau des guerres (Razrjad), qui tenait les registres des finances «avec des ruses évidentes ». Vu que le secrétaire avait découpé plusieurs feuilles dans l'un des registres de recettes, le procureur fiscal y apposa les scellés. Au cours de l'enquête menée par le panetier Šaskin, ce registre fut soigneusement examiné feuille à feuille. Aucune erreur de calcul ne fut trouvée, mais certaines feuilles avaient été soit « nettoyées» et corrigées, soit accompagnées d'ajouts et de remarques. Aux interrogatoires, Ulanov dit avoir découpé des feuilles vierges du registre, feuilles qui n'étaient ni marquées ni signées de sa main, pour les utiliser comme brouillon et non «pour profiter des revenus de Sa Majesté ». Le Sénat condamna Ulanov à 50 roubles d'amende ${ }^{60}$. D'autres abus furent plus sérieux. En 1713, les procureurs fiscaux de Moscou dénoncèrent le sous-secrétaire (pod'jačij) Krestov qui avait retenu 50 roubles de recettes sur l'entretien des recrues (rekrutskie den'gi), tandis que le commis de Mozajsk, Pontrat'ev, fut accusé du vol

57. A. Golubev, «Raspravnaja palata pri Senate (La Chambre d'instruction du Sénat), in Opisanie dokumentov i bumag, hranjaščihsja v Moskovskom arhive Ministerstva Justicii (Description des documents et des papiers conservés dans les archives du ministère de la Justice à Moscou), Saint-Pétersbourg, 1888, t. 5, p. 122.

58. Ibid., p. 127.

59. PSZ, t. 5, n 2669. Oukase du 24 avril 1713 ( O nevstupanii fiskalam ni v kakie čelobitčikovy dela » (Sur l'interdiction aux procureurs fiscaux d'intervenir dans les affaires des plaignants)).

60. RGADA,f. 248, op. 120, d. 114. 
de 72 roubles en $1722^{61}$. En 1721, les procureurs fiscaux ramenèrent de Iaroslavl à Saint-Pétersbourg le receveur Polezaev qui s'était approprié frauduleusement une partie des arrérages de l'année $1720^{62}$. Une grande enquête fut ouverte à la suite de rapports de l'ober-fiskal Nesterov à l'encontre du prince Matvej Gagarin, gouverneur de Sibérie depuis 1708. L'enquête suivie par le Bureau d'instruction (rozysknaja kanceljarija) du général-major Ivan Dmitriev-Mamonov révéla de nombreux abus. Comme gouverneur d'une région aussi éloignée de la capitale, Gagarin avait amassé une énorme fortune, grâce au commerce avec la Chine, à partir de trafics illégaux de négociants privés et de ses propres agents. Il prenait des pots-de-vin et gaspillait les revenus fiscaux, tant sous forme d'argent que de biens en nature (fourrures et diamants). Le prince Gagarin fut mis à mort publiquement le 21 mars 1721 à Saint-Pétersbourg ${ }^{63}$. Il est à remarquer que Nesterov lui-même sera contrôlé et arrêté en 1723 sur ordre du premier procureur général, Pavel I. Jagužinskij, pour les mêmes crimes que ceux qu'il poursuivait avec autant de zèle. L'arrestation de l'ober-fiskal Nesterov est révélatrice de l'ampleur du contrôle : tous les sujets du tsar, du simple roturier aux princes de l'empire, étaient susceptibles, le moment venu, d'être contrôlés sans aucune distinction. Ceux qui participaient au contrôle n'en étaient pas non plus exemptés. Le contrôle pouvait s'appliquer effectivement à l'ensemble de la société russe, les contrôleurs y compris.

Ces interventions des procureurs fiscaux leur créaient des relations difficiles avec le monde de l'administration. Les employés, des petites villes sibériennes à la nouvelle capitale, ne voyaient certainement pas l'intérêt d'être surveillés. Les gouverneurs ne voulaient ni recevoir ni examiner les rapports des procureurs fiscaux. Les agents de contrôle se plaignaient souvent des injustices des commis provinciaux qui les injuriaient et les maltraitaient. La haute administration s'opposa de même à leur contrôle. Leurs relations avec les sénateurs, prévues à l'origine pour être de collaboration, devinrent très tendues. Paradoxalement, au lieu d'aider et de diriger les procureurs fiscaux, le Sénat mettait toutes sortes d'obstacles sur leur chemin. En avril 1712, l'ober-fiskal Željabužskij et ses adjoints se plaignirent auprès du tsar de « la lenteur exorbitante des sénateurs » :

À notre entrée au Sénat, le prince Jakob Dolgorukij et le prince Grigorij Plemjannikov, sans qu'aucune faute n'ait été invoquée, se montrèrent devant nous en colère et sans bienveillance, mais de plus, ils nous réprimandèrent et nous diffamèrent de telle sorte qu'il est même devenu dangereux de leur adresser la parole ${ }^{64}$.

61. Ibid., f. 386, op. 1, d. 2 .

62. Ibid., f. 248, op. 11, kn. 608, d. 35, 1. 224-226.

63. La pratique administrative du prince Gagarin et le rôle actif du procureur fiscal Nesterov dans la révélation de ses fraudes en Sibérie sont restitués de façon détaillée par M. O. Akišin, Policejskoe gosudarstvo i sibirskoe obščestvo. Epoha Petra Velikogo (L'État policier et la société sibérienne. Époque de Pierre le Grand), Novosibirsk, 1996.

64. N. A. Voskresenskij, op. cit., t. 1, p. 331. Lettre de l'ober-fiskal Mihail Željabužskij et de ses adjoints, Aleksej Nesterov et Stepan Šepelev, au tsar, du 8 avril 1712. 
Le sénateur Plemjannikov traita les procureurs fiscaux de « juges des rues » tandis que le prince Dolgorukij les qualifia «d'Antéchrists et de fieffés coquins ${ }^{65}$. Le vice-chancelier Petr Šafirov leur interdit définitivement l'accès au collège des Affaires étrangères ${ }^{66}$. Le travail des procureurs fiscaux se compliquait donc fortement lorsque l'administration s'opposait à leur présence. Tout cela fait qu'ils ne purent plus que se concentrer sur la réception des plaintes et des dénonciations émanant de la population. La dénonciation revêtit alors des formes institutionnelles, se transformant en un véritable instrument de contrôle.

Les informateurs avaient des contacts dans tous les milieux sociaux, le plus souvent avec les contribuables qui exprimaient des plaintes. Dans l'espoir de se protéger et d'obtenir justice, les contribuables portaient à la connaissance des procureurs fiscaux les inégalités de répartition et la perception abusive des impôts dont ils étaient les premières victimes. Le pouvoir accueillit ces plaintes, mais dans l'unique but de connaître et de réprimer les abus, afin d'envisager des améliorations possibles au système fiscal.

Les procureurs fiscaux trouvaient couramment leurs informateurs parmi les employés qui signalaient les prévarications commises dans leurs départements. En 1724 , le commis Rusinov leur fit savoir que les employés du Bureau des uniformes (Mundirnaja kanceljarija) fabriquaient des habits non conformes aux modèles établis par les règlements ${ }^{67}$. Fedor Protopopov, sous-secrétaire de la Cour de monnaie de Moscou, avertit les autorités du vol d'argent auquel se seraient livrés les maîtres Banščikov et Stepanov pendant la refonte des monnaies ${ }^{68}$. La même année, le commis aux écritures Adreev dénonça devant les procureurs fiscaux les détournements de toutes sortes commis par le secrétaire de l'imprimerie moscovite. Selon lui, l'imprimerie courait à la ruine tandis que ses employés, qui ne pas touchaient plus leurs traitements depuis longtemps, vivaient dans une misère totale ${ }^{69}$. Les procureurs fiscaux s'informaient également du déroulement des enquêtes fiscales auprès des divers bureaux. C'est grâce à leur forte insistance qu'ils obtinrent les listes des affaires jugées selon leurs rapports au collège des Recettes et au collège des Dépenses ${ }^{70}$ et qu'ils purent accélérer l'examen du dossier du marchand Orlov qui demandait l'autorisation du Bureau des accises (Akciznaja kontora) pour produire du tabac à priser ${ }^{71}$.

Les oukases prescrivaient aux procureurs fiscaux de toujours protéger les dénonciateurs et de ne pas divulguer les noms de leurs collaborateurs à qui que ce soit ${ }^{72}$. Après quelques années de coopération, ceux-ci pouvaient être nommés eux-

\section{Ibid.}

66. S. Šestakov, op. cit., p. 101.

67. RGADA, f. 248 , op. 11 , kn. 608 , d. 37.

68. Ibid., f. 386, op. 1, d. 17.

69. Ibid., f. 386, op. 1, d. 36, 1. 2-4.

70. Ibid., f. 386, op. 1, d. 15, 20.

71. Ibid.,f. 386, op. 1, d. 15.

72. PSZ, t. $4, n^{\circ} 2414$. Arrêt du Sénat du 10 août 1711. 
mêmes procureurs fiscaux. Le pouvoir pénalisa la non-dénonciation en même temps qu'il accorda des primes et des gratifications pour encourager la dénonciation. Un exemple en est donné par l'affaire de Fedot'eva, propriétaire de terre, qui fut accusée en 1715 par le paysan Timofeev et le procureur fiscal Araslanov, de vente prohibée de vin. Le Sénat la condamna à payer une amende de 50 roubles dont 5 roubles revinrent à Timofeev ${ }^{73}$. La dénonciation calomnieuse ne demeurait pas non plus impunie; en témoigne l'affaire du marchand Cokurov, accusé par sa femme et par le procureur fiscal Šepelev de commercer pendant la nuit. L'enquête ne révéla aucune fraude. La femme de Cokurov fut fouettée en public, le rapport du procureur fiscal étant corrigé 74 .

Les inspections des finances (revizionnye komissii) posèrent, en tant que contrôle exceptionnel, les bases de leurs activités au début du XVIII siècle. En mettant en œuvre de nouvelles techniques de contrôle, elles pouvaient fournir au pouvoir la possibilité réelle de connaître, de l'intérieur, le monde des administrateurs et l'efficacité de leur travail. L'incorporation du contrôle à la gestion locale permettait de saisir sur place les problèmes et d'intervenir avec plus de rapidité. Mais, les inspections ne prirent pas, durant cette période, un caractère systématique. Elles n'appréhendèrent pas le secteur économique et financier dans son ensemble. La création des inspecteurs fut définie par les besoins du moment, occasion que la monarchie saisit pour éclairer l'état de ses provinces. Au début, Pierre ${ }^{\text {er }}$ décida d'y envoyer, le 4 avril 1722, des membres de chaque collège sous la présidence de l'un des sénateurs avec mission d'examiner l'administration locale dans tous les domaines. Cette décision demeura pourtant inappliquée jusqu'en novembre 1723. À cette date, de nouveaux délais apparurent, la composition et les missions des inspecteurs furent modifiées. Désormais, leur envoi sur place dépendit de l'achèvement de la réforme fiscale et correspondit à l'objectif d'observer la législation dans les finances et de contrôler le règlement des nouveaux impôts. Il fut prévu que les inspecteurs, choisis parmi les conseillers et les assesseurs du collège des Recettes, rendraient compte de leurs investigations périodiquement au moyen de rapports aux généraux et aux commandants des régiments dans leurs gouvernements. Le détail de leurs activités ne laissa pas de traces dans les archives russes ; vraisemblablement, aucune visite des inspecteurs ne fut effectuée sous Pierre le Grand.

Une autre tentative pour organiser le contrôle sur place marqua le règne de Catherine Ire. Le 17 mai 1726, à la suite des rapports de Pavel I. Jagužinskij, le comte Andrej A. Matveev, alors président des bureaux du Sénat à Moscou, reçut la mission d'inspecter la gestion et la justice à Moscou et dans les villes des alentours. « Pour l'intérêt de l'État et un meilleur gouvernement », il fallait s'informer des

73. RGADA, f. 386, op. 1, d. 2, 1. 234.

74. A. Golubev, op. cit., p. 218. Prigovor Senata po donošeniju fiskala Stepana Šepeleva o nezakonnoj torgovle kupca Cokurova (La sentence du Sénat après la dénonciation du procureur fiscal Stepan Šepelev sur le commerce illégal du marchand Cokurov) (1713). 
endroits « où il existait le plus de désordres, recevoir les plaintes du peuple et veiller aux cours de justice, aux commissaires provinciaux et aux officiers d'armés pour qu'ils perçoivent dûment l'argent et qu'ils ne commettent aucune violence dans les travaux publics $\gg^{75}$. Malgré les échéances courtes de ses activités, l'inspection mit en lumière de sérieux abus de la part de la nouvelle administration, abus qui menaçaient de dysfonctionnement le système financier et le rendaient de plus en plus désagréable aux populations. «D'inconcevables vols d'argent » furent mis au jour dans l'exécution des recettes et des dépenses dans les provinces de Vladimir et de Kostroma. Les comptables de Pereslavl'-Zalesskij « ne se voyaient aucunement en devoir de tenir les registres selon les règles, sinon sous forme de notes détériorées et entassées en désordre ». Le contrôle des caisses du commis Burnasov montra que non seulement celui-ci ne mentionnait jamais les versements faits par les contribuables, mais, à l'arrivée de Matveev, il avait transporté « tous les coffres avec les oukases et les lettres de payement dans ses villages où il les cacha longtemps ». Dans cette province, l'inspecteur engagea trente enquêtes et les opérations de restitution atteignirent 4000 roubles. À Souzdal, les détournements de deniers publics montèrent jusqu'à 4539 roubles dont 1100 roubles de podušnaja podat' furent détournés par deux commis aux écritures que Matveev condamna à mort en novembre $1726^{76}$. L'inspection de Matveev aurait pu devenir une excellente opération de contrôle exceptionnel, mais elle fut interrompue en juillet 1727 par des circonstances d'ordre politique.

La monarchie russe sous Pierre le Grand fit un grand effort pour défendre ses intérêts fiscaux et pour améliorer sa situation financière. Soucieuse d'organiser un contrôle efficace de ses finances, elle recourut à tous les moyens possibles, « classiques » comme exceptionnels, destinés à assurer un prompt fonctionnement de ses services et à réprimer les malversations et les fraudes, tant dans la perception des recettes que dans l'emploi des deniers publics. L'efficacité de l'action de contrôle ne fut pas, à l'évidence, proportionnelle aux résultats attendus. Elle connut des moments de recul et de nouveaux départs, le système complexe des finances et l'administration dont les malversations semblaient être générales restant difficiles à maîtriser. Pour autant, le décalage qui triomphait durant cette période entre les principes de contrôle énoncés et leur mise en application ne rendit pas ce contrôle aussi invisible et inefficace qu'on a tendance habituellement à le considérer. Le personnel de contrôle réussit même à tirer avantage de ces difficultés : en recherchant les moyens de mieux contrôler, il diversifia ses opérations d'investigation et les adapta à chaque situation particulière. Le nouveau système de contrôle tenta de répondre avec insistance aux problèmes de l'administration et d'assainir les finances monarchiques durant la guerre, tout en affermissant le courant des réformes engagées. Le système financier y gagna en stabilité. L'introduction d'un contrôle financier permanent par

75. RGADA, f. 9 (Kabinet Petra I), otd. 1, kn. 33.

76. À ce propos, voir S. M. Solov'ev, Istorija Rossii s drevnejših vremen (Histoire de la Russie depuis l'Antiquité), 3 éd., Moscou, Universitetskaja tipografija, 1884, t. 18, p. 295-297. 
le monarque lui permit d'être plus puissant que jamais auparavant. Sous le règne de Pierre Irer, une impulsion décisive a été donnée à une nouvelle forme de contrôle exercée par un appareil et des procédures spécialisés, qui, à partir de l'examen des affaires financières des sujets, en vint à exercer un contrôle sur toute la société. C'est cet appareil et ces procédures qui, en se développant, donnèrent naissance à l'État, si on réserve cette expression à un appareil administratif en liaison permanente avec l'ensemble de la société. Un État encore très fruste et très limité par la faible technicité de ses moyens, le faible niveau de formation de ses personnels et surtout un État qui intervient dans une société dont les usages, les pratiques et les habitudes qui scellent les relations sociales et font naître les échanges lui sont encore largement contraires. L'ampleur de la réforme pétrovienne - le contrôle des finances en fait partie - se heurte là au socle social et culturel d'une société qui n'a pas encore connu et vécu une telle forme de l'exercice du pouvoir, fût-il le plus grand selon ses justifications.

natalia.platonova@oreka.com 